the category fallacy which Gilbert Ryle (1949) described as the 'dogma of the Ghost in the Machine'. There is no empirical evidence of a single cortical area which all other cortical areas report exclusively to either in the visual or in any other system (Zeki, 1993). This suggests both that the brain must be using a different strategy for generating integrated mental experiences (i.e. solving the binding problem) and for answering the question of who is looking at a visual image. The current hypothesis, which is in itself inadequate, is that our awareness of our mental experiences as an integrated whole is the result of the synchronised firing of all the neurones symbolising all the different attributes of, for example, a single object (shape, colour, movement, etc) (Crick, 1994). In other words, our unified perceptual experiences do not depend upon an homunculus.

Charlton, B. G. (1995) Cognitive neuropsychiatry and the future of diagnosis: a 'PC' model of the mind. British Journal of Psychiatry, 167, 149-158.

Crick, F. (1994) The Astonishing Hypothesis. London: Touchstone Books.

Ellis, H. D., Whitley, J. \& Luaute, J-P. (1994) Delusional misidentification: the three original papers on Capgras, Fregoli and intermetamorphosis delusions. History of Psychiatry, 5, 117-146.

Ryle, G. (1949) The Concept of Mind. London: Penguin.

ZEKI, S. (1993) A Vision of the Brain. Oxford: Blackwell Scientific.

The Queen Elizabeth Psychiatric Hospital

F. OYEBODE

Birmingham B15 2QZ

\section{Lead-in placebo washout period}

SIR: A reviewer of the multi-centre risperidone trial report pointed out the dubious utility of the one week lead-in washout period (Johnson \& Johnson, 1995). This is an important issue that merits attention. The principal purpose of the washout period is to metabolise and eliminate the previous medication. As the reviewer points out, and as available data demonstrate (Cohen et al, 1988), one week is far too short to accomplish that goal. Nevertheless, sudden discontinuation of the previous treatment for several days may result in clinical deterioration; in this risperidone trial, the deterioration was severe enough to necessitate a shortened washout in $17 \%$ of the patients (Peuskens, 1995). Delaying treatment or withdrawing it has ethical and economical costs. If the principal purpose of the washout period is not achieved, why incur these costs?

To answer this question, it may be suggested that a partial washout is better than none. But I am not sure that this is self-evident. Another possible justification is that the washout period allows the establishment of the "true baseline" (Kane et al, 1994). But it is not clear what the "true baseline" means. If it means psychopathology in an untreated state, this would not apply to patients who have been receiving treatment until a week ago and whose brains still contain substantial amounts of the medication. Furthermore, placebo washout period might be justified as a method to screen for and eliminate placebo responders. But data on placebo responders eliminated from antipsychotic trials are hard to find. Finally, one might say that the washout is needed to eliminate the effects of the street drugs. But this purpose could be met in other ways, without withdrawing or delaying antipsychotic medication.

The washout period was introduced decades ago; at that time, pharmacokinetic data were not available, and ethical as well as economical concerns were different. The merits of the washout were questioned and an alternative method using an initial low-dose haloperidol treatment period was suggested (Hirsch \& Barnes, 1990). Nevertheless, the washout period continues to be a standard component of antipsychotic trials. It is time to reconsider its justification

Cohen, B. M., Babb, S., Campbell, A., et al (1988) Persistence of haloperidol in the brain. Archives of General Psychiatry, 45, 879-880.

Hirsch, S. R. \& Barnes, T. R. E. (1990) Testing the efficacy of new neuroleptic drugs. Methodology of the Evaluation of Psychotropic Drugs. Psychopharmacology Series 8 (eds O. Benkert. W. Maier \& K. Rickels), p. 26. Berlin: Springer-Verlag.

Johnson, A. L. \& Johnson, D. A. W. (1995) Peer review of "Risperidone in the treatment of patients with chronic schizophrenia: a multi-national, multi-centre, double-blind, parallelgroup study versus haloperidol". British Journal of Psychiatry. 166, 727-733.

KANE, J. M., SChoOler, N. R., MARDER, S. R., et al (1994) Methods for clinical evaluation of pharmacologic treatments of schizophrenia. Clinical Evaluation of Psychotropic Drugs. Principles and Guidelines (eds R. F. Prien \& D. S. Robinson), p. 345. New York: Raven Press.

PEuskens, J. (1995) Risperidone in the treatment of patients with chronic schizophrenia: a multi-national, multi-centre, doubleblind, parallel-group study versus haloperidol. British Journal of Psychiatry, 166, 712-726.

J. Volavka

Nathan Kline Institute

Orangeburg

NY 10962, USA

\section{Obstetric complications in schizophrenia}

SIR: The interesting findings of the British Perinatal Mortality Survey study by Sacker et al (1995) which found an excess of obstetric complications (OCs) in 
patients with schizophrenia $(n=35)$ compared to controls $(n=16812)$, are obscured by the authors' interpretation and conclusions.

It is proposed that OCs are under-reported in mothers of controls, whereas in mothers of schizophrenics, as a result of their subtle behavioural problems and a poorer obstetric history, they are monitored more closely by midwives and OCs are more accurately reported. The authors hypothesise that this explains the higher rates of OCs in schizophrenic patients $v$. controls that have been reported in the voluminous literature on the subject. This hypothesis appears to be based not on an examination of the previous literature, nor on any direct testing of the hypothesis in their own study, but solely on the basis that mothers of schizophrenics in their study had a poorer obstetric history and more behavioural problems than controls and on their suspicion that OCs have been under-reported in controls in previous studies. The hypothesis does not bear closer examination.

Firstly, many previous studies which found an excess of OCs in schizophrenics used normal siblings as the control group. Clearly as both the subjects and controls had the same mother, maternal differences cannot be invoked to explain different OC rates. Secondly, as the authors state in their introduction "certain OCs will be more salient to the midwife and will therefore be recorded in the birth records, while other less salient factors will be under-reported". The specific OCs which have been found to be significantly elevated in schizophrenics compared to controls, are, in almost all studies, complications such as low birthweight, prematurity, prolonged labour, abnormal fetal position, umbilical cord encircling and knot, premature rupture of membranes and asphyxia, all of which are clearly salient and unlikely to be under-reported in controls. Indeed, the authors own study, which relied on birth records, is one of the few examples of a study which focuses on 'less salient' OCs, and their findings of increased smoking in pregnancy and poor obstetric history in mothers of schizophrenics could thus be justifiably questioned on the basis of their own hypothesis.

In the authors discussion about the relationship between OCs and affective disorder they state that "in contrast to the work on OCs and schizophrenia, there is remarkable consistency between our findings ... and the work of Kinney et al (1993). Both studies find the mothers to be older, with the births characterised by lower birth weight and forceps deliveries". This is in fact not the case and misleading. Kinney et al, in a study of 16 probands and 20 siblings, found an increase in summary total $O C$ scores but in fact "... No single OC was significantly more prevalent in (bipolar) probands than in their unaffected sibs ...". Forceps delivery and low birth weight were just 2 of 15 single OCs present in at least one subject, none of which were significantly elevated in bipolar probands. Noticeably, there is remarkable consistency between Sacker et als findings and a previous study of 73 schizophrenic patients (Rifkin et al, 1994). In both studies $15 \%$ of schizophrenic probands were born with low birth weight $(<2500 \mathrm{~g})$, both studies found low birth weight to be the only individual $O C$ to be significantly elevated in comparison to controls and the mean birth weights in schizophrenic probands was almost identical $(3174 \mathrm{~g} v .3175 \mathrm{~g})$. Two further published studies have reported significantly lower mean birth weight in schizophrenics $v$. controls (Lane \& Albee, 1966; McNeil et al, 1993).

The authors also speculate about the role of genetic liability and raise the question of whether the behavioural problems in the mothers of schizophrenics could be considered as part of a broad phenotype of schizophrenia. Given this speculation, it is unclear why it was possible to identify through patients' case notes those mothers with a history of affective disorder, and remove them from the analysis but a similar procedure was not applied to the schizophrenic group. It should also be noted that the issue of whether variables of maternal characteristics and those relating to the current pregnancy, birth and the baby's condition (in particular, antenatal bleeding, baby's weight) are an independent risk factor for developing schizophrenia can be tested in the framework of a logistic regression analysis.

KinNey, D. K., Yurgelun-TodD, D. A., LeVy, D. L., et al (1993) Obstetric complications in patients with bipolar disorder and their siblings. Psychiatry Research, 48, 47-56.

LANE, E. A. \& AlBEE, G. W. (1966) Comparative birth weights of schizophrenics and their siblings. Journal of Psychology. 65, 227-231.

MCNeil, T. F., Cantor-GraAe. E., Nordstrom, L. G., et al (1993) Head circumference in 'preschizophrenic' and control neonates. British Journal of Psychiatry. 162, 517-523.

RIFKIN, L., LewIS, S., Jones, P. B. et al (1994) Low birth weight and schizophrenia. British Journal of Psychiatry, 165, 357-362.

SACKer, A., Done, D. J., Crow, T. J., et al (1995) Antecedents of schizophrenia and affective illness: obstetric complications. British Journal of Psychiatry, 166, 734-741.

L. RIFKIN

Institute of Psychiatry

N. TAKEI

London SE5 8 AF

SIR: Sacker et al (1995) suggest that the reported association between obstetric complications (OCs) 